\title{
A Novel, Sensitive Method to Evaluate Potato Germplasm for Bacterial Wilt Resistance Using a Luminescent Ralstonia solanacearum Reporter Strain
}

\author{
Andrea Paola Zuluaga Cruz,, ${ }^{1,2}$ Virginia Ferreira, ${ }^{3}$ María Julia Pianzzola, ${ }^{3}$ María Inés Siri, ${ }^{3}$ Núria S. Coll,, \\ and Marc Valls ${ }^{1,2}$ \\ ${ }^{1}$ Departament de Genètica, Universitat de Barcelona, Av. Diagonal 643, Catalonia, Spain; ${ }^{2}$ Centre for Research in Agricultural \\ Genomics (CRAG), Edifici CRAG, Campus UAB, 08193 Bellaterra, Catalonia, Spain; ${ }^{3}$ Cátedra de Microbiología, Dep. \\ de Biociencias, Facultad de Química, Universidad de la República, Av. Gral. Flores 2124, CP11800, Montevideo, Uruguay
}

Submitted 11 October 2013. Accepted 20 November 2013.

Several breeding programs are under way to introduce resistance to bacterial wilt caused by Ralstonia solanacearum in solanaceous crops. The lack of screening methods allowing easy measurement of pathogen colonization and the inability to detect latent (i.e., symptomless) infections are major limitations when evaluating resistance to this disease in plant germplasm. We describe a new method to study the interaction between $R$. solanacearum and potato germplasm that overcomes these restrictions. The $R$. solanacearum UY031 was genetically modified to constitutively generate light from a synthetic $\operatorname{lux} C D A B E$ operon stably inserted in its chromosome. Colonization of this reporter strain on different potato accessions was followed using life imaging. Bacterial detection in planta by this nondisruptive system correlated with the development of wilting symptoms. In addition, we demonstrated that quantitative detection of the recombinant strain using a luminometer can identify latent infections on symptomless potato plants. We have developed a novel, unsophisticated, and accurate method for high-throughput evaluation of pathogen colonization in plant populations. We applied this method to compare the behavior of potato accessions with contrasting resistance to $R$. solanacearum. This new system will be especially useful to detect latency in symptomless parental lines before their inclusion in long-term breeding programs for disease resistance.

Bacterial wilt caused by Ralstonia solanacearum is one of the world's most devastating bacterial diseases of plants (Peeters et al. 2013). It is present worldwide, threatening food safety of small producers in tropical and subtropical areas, especially in China, Bangladesh, Bolivia, and Uganda (Martin and French 1985; Muthoni et al. 2012). However, because the pathogen disseminates easily to long distances via infected plant material (Hayward and Pegg 2013; Janse et al. 2004), there has been a recent spread of the disease to temperate

\section{A. P. Z. Cruz and V. Ferreira contributed equally to this work.}

Corresponding author: N. S. Coll;

E-mail: nuria.sanchez-coll@cragenomica.es

* The $\boldsymbol{e}$-Xtra logo stands for "electronic extra" and indicates that six supplementary figures and three supplementary tables are published online.

(C) 2014 The American Phytopathological Society regions (Genin and Boucher 2004). R. solanacearum exhibits an extremely wide host range, causing bacterial wilt on more than 200 plant species, including commercially important crops such as potato, tomato, and banana (Hayward 1991). Wilting symptoms are caused by extensive multiplication of the bacterium in the xylem vessels, which hinders water flow in the plant. In addition, the bacterium can colonize asymptomatically several weeds that act as pathogen reservoirs (Genin and Denny 2012) and survive in waterways and soil for long periods (Caruso et al. 2005; Elphinstone 2005). These facts, together with the lack of resistant commercial varieties in any of its hosts (Hong et al. 2005), render the control of bacterial wilt very challenging.

$R$. solanacearum is considered a species complex, divided into four phylotypes which roughly reflect their geographic origin: phylotype I groups strains from Asia, phylotype II from the Americas, phylotype III from Africa, and phylotype IV from Indonesia (Peeters et al. 2013). Each phylotype is subdivided into different sequevars which are clusters of isolates with highly conserved DNA sequences (Fegan and Prior 2005). Strains belonging to the phylotype IIB, sequevar 1 (IIB1) are the main strains responsible for bacterial wilt of potato in cold and temperate regions (Denny 2006). Moreover, IIB1 strains have the ability to produce symptomless latent infections, which facilitates the dissemination of the pathogen worldwide, hindering disease control (Janse 1996; Swanson et al. 2005; Williamson et al. 2002). UY031 is a highly aggressive strain that belongs to this sequevar and was isolated from potato tubers in 2003 in Uruguay (Siri and Pianzzola 2011; Siri et al. 2009).

Effective resistance against $R$. solanacearum is lacking in commercial varieties of any of its host crops (Hong et al. 2005). However, loci providing quantitative resistance have been identified in tobacco (Qian et al. 2012), tomato (Carmeille et al. 2006; Wang et al. 2013), and eggplant (Lebeau et al. 2013). In potato, breeding programs for resistance to bacterial wilt have used wild species related to Solanum tuberosum as sources of resistance (Narancio et al. 2013; Sequeira and Rowe 1969). Initially, $S$. phureja was used to successfully introgress resistance (Carputo et al. 2009; French and De Lindo 1982; Sequeira and Rowe 1969). More recently, the tuber-bearing species $S$. commersonii Dun (Hawkes 1994) has emerged as a source of high resistance against bacterial wilt. This wild species exhibits a high genetic diversity (Pianzzola et al. 2005; Siri et al. 2009) and encodes many desirable traits, such as tolerance to low temperatures and resistance to several pathogens, including $R$. solanacearum 
(Carputo et al. 2009; Galván et al. 2006; Gonzalez et al. 2013; Kim-Lee et al. 2005; Laferriere et al. 1999; Narancio et al. 2013; Siri et al. 2009). Due to these valuable traits, $S$. commersonii is being used as the main genetic resource for the potato breeding program held in Uruguay, focused on the development of improved potato varieties with high levels of field resistance to bacterial wilt (Galván et al. 2006; Gonzalez et al. 2013; Narancio et al. 2013).

Germplasm showing resistance to $R$. solanacearum at high altitudes often becomes susceptible when grown at warmer temperatures in the lowlands (French and De Lindo 1982; Tung et al. 1990). This suggests the existence of latent infections (i.e., infected plants that remain asymptomatic), adding further complexity to breeding programs for resistance to bacterial wilt. Latency may be a widespread phenomenon also influenced by the bacterial genotype. For instance, some $R$. solanacearum strains are pathogenic on solanaceae and cucurbits but can colonize and grow latently on banana without causing disease (Wicker et al. 2007). In addition, it is known that wilting symptoms do not always correlate with the amount of bacteria present in the plant (Angot et al. 2006; Hirsch et al. 2002).

To guarantee success of long-term breeding programs, it is extremely important to develop screening methods that allow easy tracking and quantification of bacterial colonization and latency in plants. Fan and colleagues (2008) developed a highthroughput method to evaluate Pseudomonas syringae growth in planta by inserting the $\operatorname{lu} x C D A B E$ operon in the bacterium, which was used to evaluate more than 100 Arabidopsis ecotypes for resistance against this pathogen. In a previous work, $R$. solanacearum YN5 was transformed with a plasmid carrying the luxCDABE operon to qualitatively study pathogen colonization in susceptible and resistant tomato (Hikichi et al. 1999). Recently, we showed that the $R$. solanacearum GMI1000 bearing an entire synthetic lux operon could be visualized inside infected plants (Monteiro et al. 2012a). An advantage of this system is that the reporter is stably inserted in monocopy in the bacterial chromosome, avoiding reporter loss in competitive conditions (e.g., during plant infection) and variations in reporter copy number. Here, we have improved the reporter system to ensure its continuous expression and introduced it in the highly aggressive $R$. solanacearum UY031 (Siri and Pianzzola 2011; Siri et al. 2009), which has been genetically modified for the first time to constitutively emit light while maintaining its virulence on potato. As shown by the data presented here, the modified strain can be efficiently used to follow bacterial multiplication in potato plants. Our results reveal a general correlation of pathogen colonization with disease symptoms and unveil latent infections in symptomless plants. We show that this tool can be used to easily assess the levels of resistance of germplasm collections toward bacterial wilt as well as to study latency.

\section{RESULTS AND DISCUSSION}

\section{Generation of a constitutively luminescent UY031 reporter strain.}

To allow accurate, high-throughput quantification of bacterial colonization on potato populations, we generated a luminescent variant of $R$. solanacearum UY031, a strain highly aggressive on potato (Siri and Pianzzola 2011; Siri et al. 2009). Genetic stability of the luminescent reporter was ensured by using the pRC system, which allows integration of genetic elements in a precise position of the $R$. solanacearum genome (Monteiro et al. 2012b). To guarantee high reporter gene expression in $R$. solanacearum, we cloned the constitutive chloroplast promoter PpsbA upstream of the luxCDABE operon, creating the delivery plasmid pRCG-Pps-lux. After two steps of natural transformation and selection of double recombination events (discussed below), we obtained strain UY031 Ppslux, which carries a PpsbA::LuxCDABE fusion accompanied by a gentamicin-resistance cassette inserted downstream of the $G \ln S$ gene in the chromosome. The integrated sequences were flanked by transcriptional terminators to avoid read-through to and from the neighboring chromosomal regions. UY031 Ppslux was highly luminescent, as could be visualized by introducing the transformation plates in a light imager (not shown). To verify constitutive expression of the lux reporter, the modified strain was grown in liquid culture and both bacterial growth and luminescence were measured at different time points. The correlation between the optical density at $600 \mathrm{~nm}$ $\left(\mathrm{OD}_{600}\right)$ and the luminescence of bacterial cultures is shown in Supplementary Figure S1. To determine the sensitivity of the reporter, cell suspensions of the wild-type UY031 strain or its Pps-lux counterpart carrying the PpsbA::luxCDABE reporter fusion were serially diluted 10 -fold and luminescence was recorded using a luminometer (Supplementary Table S1). It can be observed from these two experiments that the ratio of light emission (relative luminescence units [RLU]) with respect to cell number remains constant throughout growth and that luminescence can be measured from $\mathrm{OD}_{600}=0.0001$ (i.e., $10^{5}$ cells per milliliter). To further ascertain the effect of different environmental conditions on the expression of the lux reporter, we grew the strains in rich or minimal media and measured luminescence and bacterial growth over time. The ratio between light emission and bacterial cell density varied only slightly (20 to $30 \%$ ) in bacteria growing in both media used (Supplementary Table S2).

\section{Modified UY031 reporter strains are not affected in growth or pathogenicity on potato.}

Integration of the foreign genes in the UY031 genome and the high expression of the lux reporter could cause a drawback to bacterial fitness. Although gene integration in the homologous region in strain GMI1000 was found to be permissive (Monteiro et al. 2012b), we wanted to ascertain whether the insertion of a constitutively expressed lux operon had an impact on the growth or pathogenicity of UY031. We evaluated the pathogenicity of the UY031 Pps-lux strain in comparison with the wild type on potato (Fig. 1A) and on S. commersonii (Fig. 1B) by measuring the evolution of wilting symptoms over time after soil inoculation. To better analyze a possible influence of the reporter construct on pathogenicity, the contribution of the $P p s b A$ promoter or the luxCDABE reporter operon were determined by including strains containing these elements fused to the green fluorescent protein (UY031 Pps-GFP) or to the promoter driving exopolysaccharide expression (UY031 Pep-lux). For better comparison, Figure $1 \mathrm{C}$ presents the values corresponding to the area under the disease progress curve (AUDPC), based on the average wilting score for each combination of strain and host. No significant differences in aggressiveness were found between the wild type and the reporter strain $(P=$ 0.4604 and 0.2181 for $S$. tuberosum and $S$. commersonii, respectively). These results, together with the fact that the modified strains showed no growth defects in liquid B or minimal medium, demonstrate that the targeted region in UY031 chromosome is a permissive site for integration of genetic constructs and that constitutive expression of the lux operon does not affect growth or pathogenicity of the modified $R$. solanacearum strains.

\section{Disease progression can be efficiently evaluated by detecting bacterial light emission in planta.}

Once we had created a bacterial reporter strain that constitutively emitted light without affecting virulence, we tested 
whether it could be used to measure bacterial colonization on potato. To this end, we soil-drench inoculated the luminescent $R$. solanacearum UY031 Pps-lux strain on $S$. commersonii accessions F97 and F118, which have shown tolerance to bacterial wilt in laboratory assays (Gonzalez et al. 2013; Narancio et al. 2013). Disease symptoms and light emission from the aerial parts of the plants were recorded for up to 7 days after inoculation. Because luminescence detection is a nondisruptive detection method, disease progression could be followed in the same plants over time. Time-course evaluation of luminescence (top panels) and wilting symptoms (lower panels) are shown in a representative, readily colonized plant of each S. commersonii accession: F97 (Fig. 2A) and F118 (Fig. 2B). It can be observed that symptom appearance correlated with the extent of light emission, which increased over time. This demonstrated that live imaging of luminescent strains in planta reflects the degree of bacterial colonization, providing a sensitive and reliable method for phenotypical disease evaluation. Interestingly, detection of luminescent (dark) areas using the imaging system frequently preceded symptom appearance, testifying to the higher sensitivity of luminescence to evaluate disease progression compared with visual symptom recordings.

\section{Luminescence detection is not influenced} by infection stochasticity.

For any given plant infected with UY031 Pps-lux, progression of luminescence over time always showed a good correlation with external symptoms. However, comparable bacterial loads-as measured by the extent of light-emitting tissuecorresponded to variable symptom severity in different plants. Such an example of different degrees of plant wilting for a similar extent of bacterial colonization is shown in Figure 3. Symptom variability may be attributed to a strong influence of the plant physiological status on wilting development but it could also reflect stochasticity due to the location of the infection. For instance, low infection of various vascular bundles may cause more wilting than extensive colonization limited to a few xylem vessels. Thus, luminescence is a more robust measure of plant colonization, less influenced by the environmental conditions or stochastic variations than visual phenotypic observation of wilting symptoms.

\section{Luminescence can be used}

to quantify bacterial content inside plant tissues.

In our experiments with the $R$. solanacearum strain carrying the lux operon, we often found asymptomatic plants in which
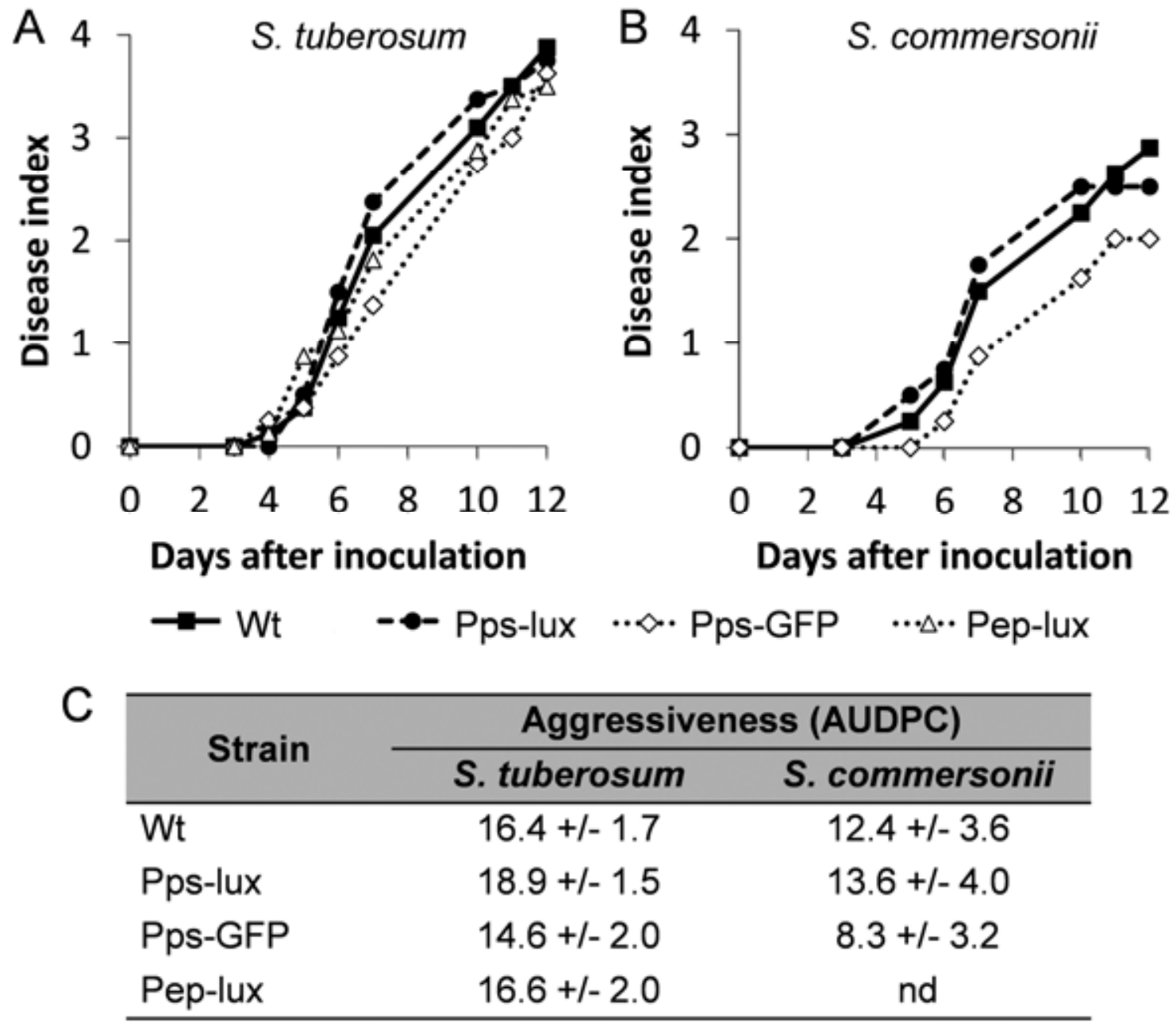

Fig. 1. Aggressiveness of Ralstonia sonlanacearum reporter strains on potato (Solanum tuberosum 'Chieftain') and the wild potato species $S$. commersonii (accession F118). Bacterial wilt progress curves on $\mathbf{A}, S$. tuberosum Chieftain and $\mathbf{B}, S$. commersonii after soil inoculation with $R$. sonlanacearum strain UY031 and its reporter derivative strains UY031 Pps-Lux, UY031 Pps-GFP, and UY031 Pep-lux. Each data point represents the mean of two experiments with four replicates, for a total of eight replicates per strain. C, Area under the disease progress curve (AUDPC) for the average wilting rating caused by each strain represented in A (S. tuberosum) and B (S. commersonii) \pm standard errors. Values are means of two independent experiments on each host. Data were pooled across trials of repeated experiments because no significant effects involving trials were found in the analyses of variance. No significant differences were observed among AUDPC values for all tested strains $(P=0.05)$; nd $=$ not determined. 
bacterial colonization was detected as emission of light from infected stems (Fig. 2A). On some occasions, we identified wilted plants where light-emitting bacteria could not be detected in the aerial part. Examples of this can be observed in Figure 4, displaying S. commersonii plants from both the F97 and F118 genotypes with extensive wilting symptoms (80 to $100 \%$ wilting) (Fig. 4A) not presenting any bacterial luminescence when exposed to the light imaging system (Fig. 4B). We hypothesized that, similarly to what was observed in the stems, symptoms are more influenced by variability in the location of the infected area. These plants should bear extensive colonization affecting only the underground tissues, which could cause obstruction of the xylem vessels and plant wilting. To test this, we uprooted the wilted plants showing no luminescence in stems and exposed the roots to the light-detection system. Luminescence from the roots was clearly detectable (Supplementary Fig. S2) but could not be correlated with that of the stems, due to the smaller diameter of the roots, which affected sensitivity. To better evaluate pathogen content in the root system and compare it with that of the aerial parts, we harvested sections of the stem and the root system and measured luminescence quantitatively with a luminometer. Such measurements from tissue sections of the three plants photographed in Figure 4A and B related to their tissue mass are shown in Figure 4C. As expected, high levels of luminescence were detected in the roots, indicating high pathogen content in these tissues. It should also be noted that, although at $>10$-fold lower levels, luminescence was readily measured in the stem as well, testifying to the high sensitivity of this detection procedure. In order to verify that light emission reflected the amount of bacteria in the plant, we ground tissue sections showing various levels of luminescence and plated dilutions on selective plates. A linear correlation between measured luminescence (RLU values were obtained from 1-ml aliquots) and the corresponding CFU recovered from the same tissues is demonstrated in Supplementary Fig. S3.

\section{The UY031 Psb-lux strain can be used} to reveal latent infections.

As mentioned before, latent (i.e., symptomless) infections are a major problem in breeding programs that use symptom

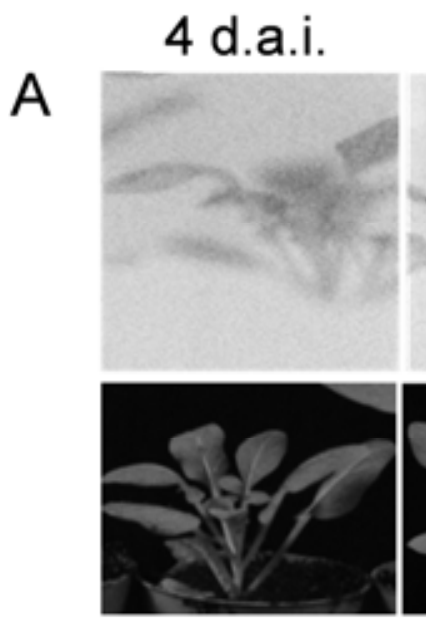

5 d.a.i.
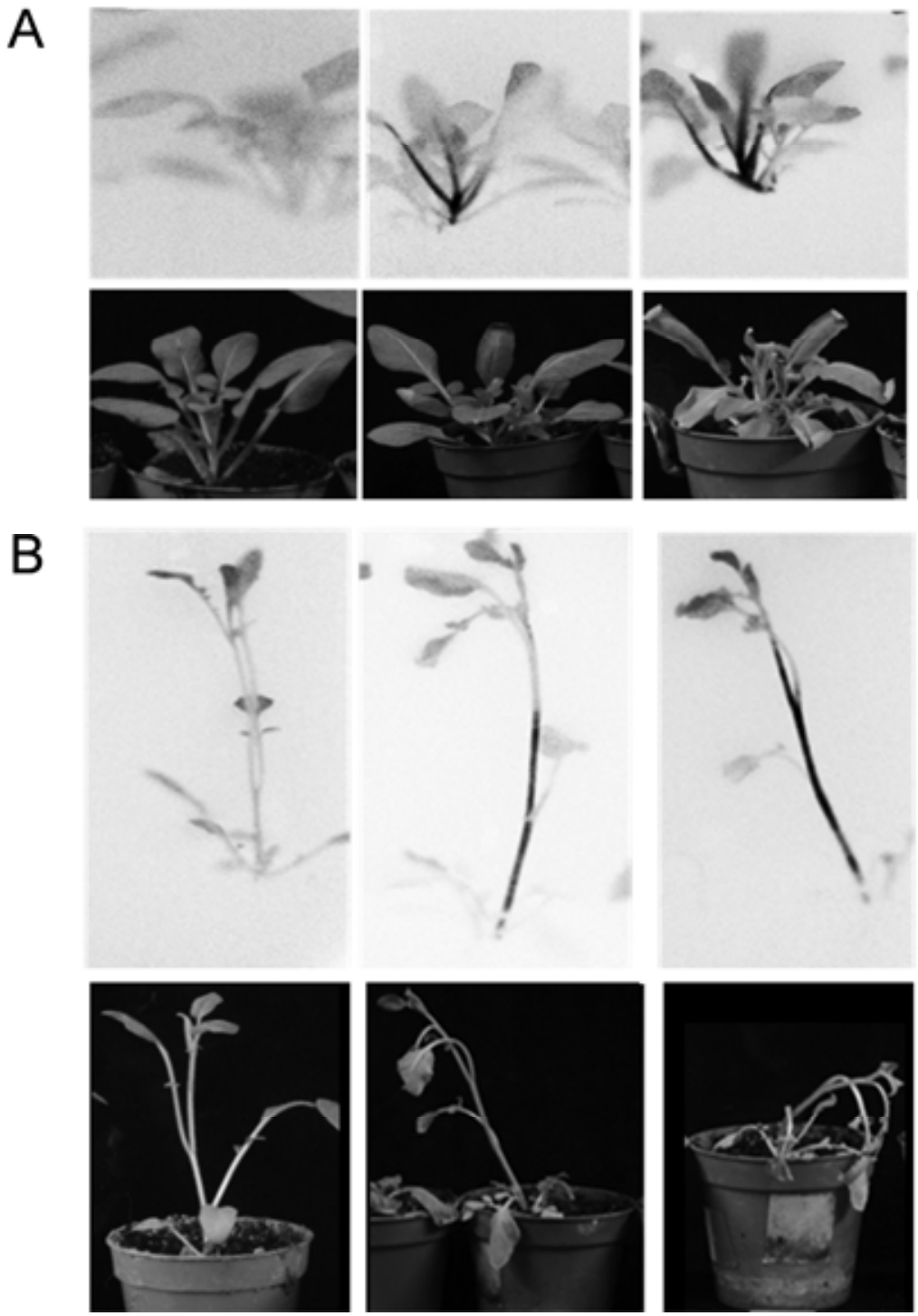

6 d.a.i.
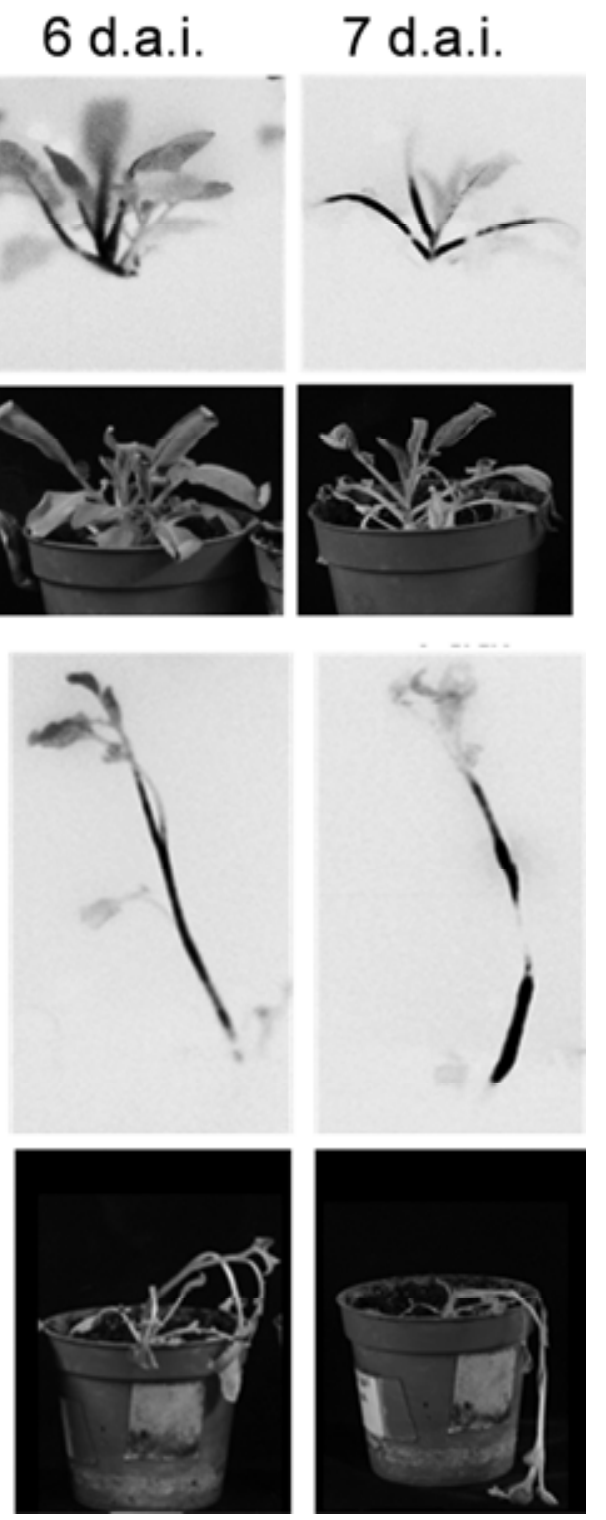

Fig. 2. Time-course evaluation of bacterial wilt on single plants of A, F97 and B, F118 Solanum commersonii accessions inoculated with UY031 Pps-lux. Upper panels show bacterial light emission measured in the dark with a light imaging system using the luminescence detection mode and lower panels show normal light pictures 4, 5, 6, and 7 days after inoculation (dai). Light gray indicates background luminescence due to chlorophyll; black regions are tissue areas colonized by light-emitting bacteria. 
scoring as the criterion of selection for resistance to bacterial wilt. Because the newly developed $R$. solanacearum reporter strain could be easily identified in potato stems well before the appearance of external symptoms (Fig. 2), we checked whether latent infections in potato roots could also be detected. We selected S. commersonii plants of accession F118 that remained asymptomatic and without bacterial stem colonization at day seven after inoculation (Fig. 5A and B)-a time when most F97 plants were wilted-and the luminescence of root and shoot sections was quantified with a luminometer (Fig. 5C). Bacterial colonization was detected in the root system of some of the symptomless plants by faint but distinct luminescence measures significantly above background levels, set approximately $10 \mathrm{RLU} / \mathrm{mg}$ using plants infected with an untransformed strain (Supplementary Fig. S6). In contrast, infection of aerial parts was never recorded in these symptomless plants. Thus, in the conditions used for our pathogenicity assays, latency was typically identified as low bacterial numbers confined to the primary infected tissues. Notice that the pathogen was undetectable in some plants (e.g., F118-9 in Figure 5), consistent with the higher tolerance of the F118 genotype against $R$. solanacearum compared with F97 (discussed below). This absence was confirmed by grinding plant tissue and plating in a selective medium (not shown), which indicates the high sensitivity of the luminometer measurements.

\section{A novel tool to evaluate resistance to bacterial wilt.}

To validate the utility of the luminescent strain developed here for evaluation of plant germplasm, we analyzed a number of potato accessions combining the assays described above. We used the previously described S. commersonnii accessions F118 (tolerant) and F97 (susceptible) but, for better comparison, we also added to the assays another tolerant $S$. commer-
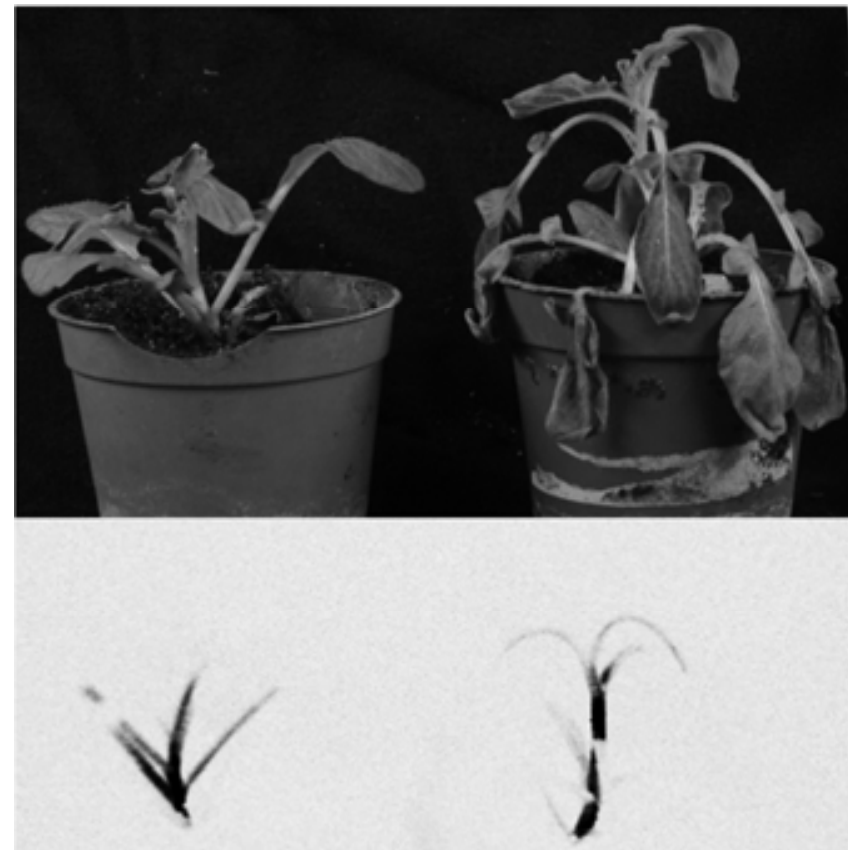

Fig. 3. Plants with comparable bacterial colonization may show different extents of wilting. Pictures show a light image (top) and luminescence detection (bottom) of two Solanum commersonii F97 plants infected with UY031 Pps-lux and displaying contrasting wilting phenotypes. The plant on the left was rated $<12 \%$ wilting, whereas the right one showed almost $75 \%$ wilting. In contrast, light emission capture of plants exposed in the dark showed that the stems of both plants were completely colonized by bacteria. sonnii accession (F100) and a susceptible commercial potato variety: S. tuberosum 'Chieftain' (CHF). CHF, F97, F100, and F118 plants were inoculated with the luminescent $R$. solanacearum UY031 Pps-lux strain and wilting symptoms were recorded over time (Supplementary Fig. S4). When plants of the commercial potato cultivar were totally wilted, we selected the remaining symptomless plants (one plant from accession F97, six from F118, and four from F100) and measured luminescence from their aerial tissues (Supplementary Fig. S5) and from their roots. The chart in Figure 6 combines all this information for the different genotypes at 7 days postinoculation: average wilting symptoms in percentage, percentage of plants showing luminescence on the aerial tissues, and percentage of plants showing luminescence on the roots. Consistent with what was expected, the more tolerant genotypes (F100 and F118) clearly showed fewer disease symptoms and less bacterial colonization than the susceptible variants (F97 and $\mathrm{CHF}$ ). Again, the presence of wilting symptoms always correlated with the presence of bacteria in the aerial tissues detected by luminescence. Interestingly, when luminescence from root tissues was measured with a luminometer, all F100 accession plants showed detectable light emission, indicating latent infections, whereas almost $40 \%$ of the F118 plants showed absence of bacteria in the roots. Thus, our method revealed clear differences in latency and resistance among genotypes, proving its utility to assist in breeding programs. Our experiments, performed with a small set of plants, showed that plants of the
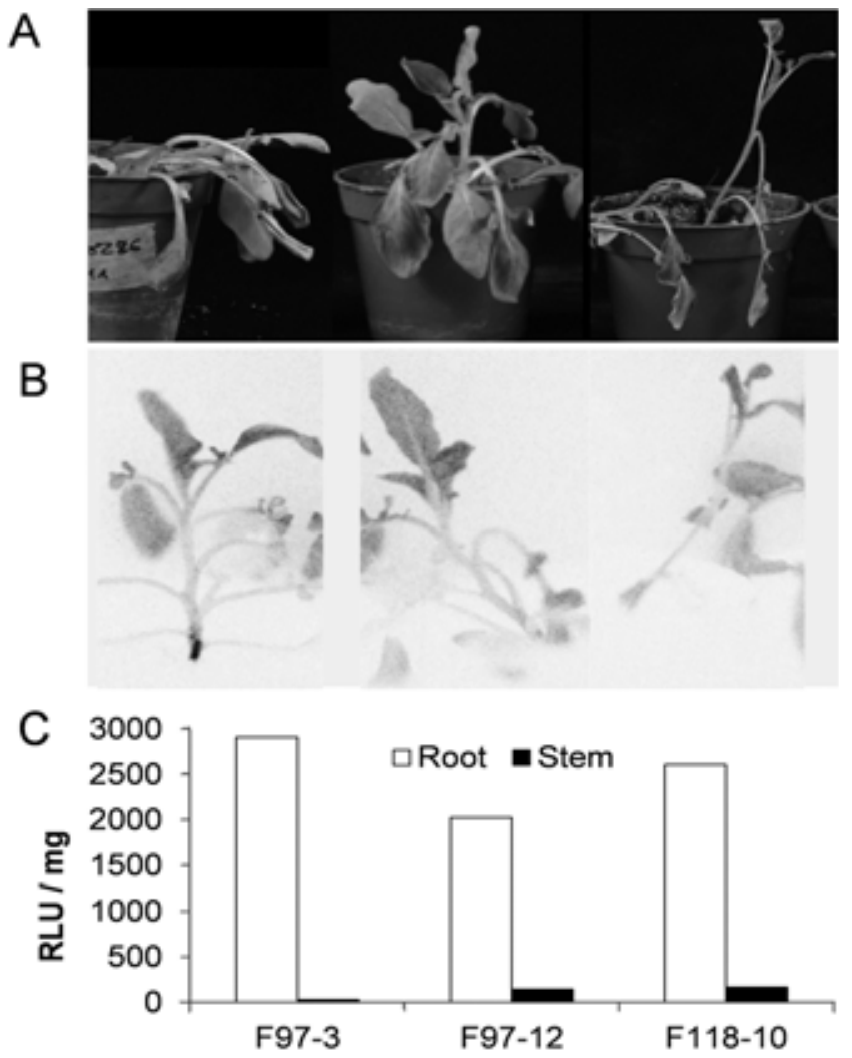

Fig. 4. Bacterial colonization of the root system of wilted plants. A, Light picture of Solanum commersonii plants of the F97 or F118 accessions exhibiting wilting symptoms at 7 days after inoculation with Ralstonia solanacearum carrying the lux operon (UY031 Pps-lux). B, UY031 Pps-lux luminescence detection of plants in A showing undetectable bacterial colonization throughout the stem. $\mathbf{C}$, Bacterial load in the root and the stem of the plants shown above. Plants were uprooted and bacterial abundance estimated by measuring luminescence of cut root or stem sections with a luminometer. Light emission from the reporter strain is presented as relative luminescence units (RLU) per milligram of tissue. 
tolerant varieties F100 and F118 carried $R$. solanacearum in the root, a sign of bacterial latency that would go undetected using other germplasm evaluation methods. It is worth noting that we used an aggressive inoculation method, drenching soil with high bacterial concentrations after root damage. The presence of totally resistant F118 plants (i.e., bacteria-free) under these harsh laboratory conditions suggests that F118 or other improved potato accessions may display even higher resistance and lower latency under milder, natural field conditions.

\section{Luminescent bacterial strains} to facilitate breeding programs.

The objective of our work was to implement a sensitive, easy-to-use method to quantify bacterial wilt resistance, improving the criteria for selection of promising resistant genotypes in breeding programs. Because tolerant individual plants might have high counts of bacteria without showing symptoms, the luminescent strain described here can be especially suited to better visualize colonization in planta and assist in breeding for resistance toward bacterial wilt. We propose the combined use of luminescence detection and symptom recording to better screen and evaluate resistant genotypes.

The flow chart in Figure 7 summarizes the different steps where a luminescent reporter strain can facilitate the selection procedure. In a first step, germplasm infected with the modified strain is scored by the classical symptom appearance. Once symptomless genotypes are identified, they can be screened for a lack of bacterial colonization in the stems by daily exposition to a light imaging system in a time-course experiment. As shown above, plants selected by this nondisrup-
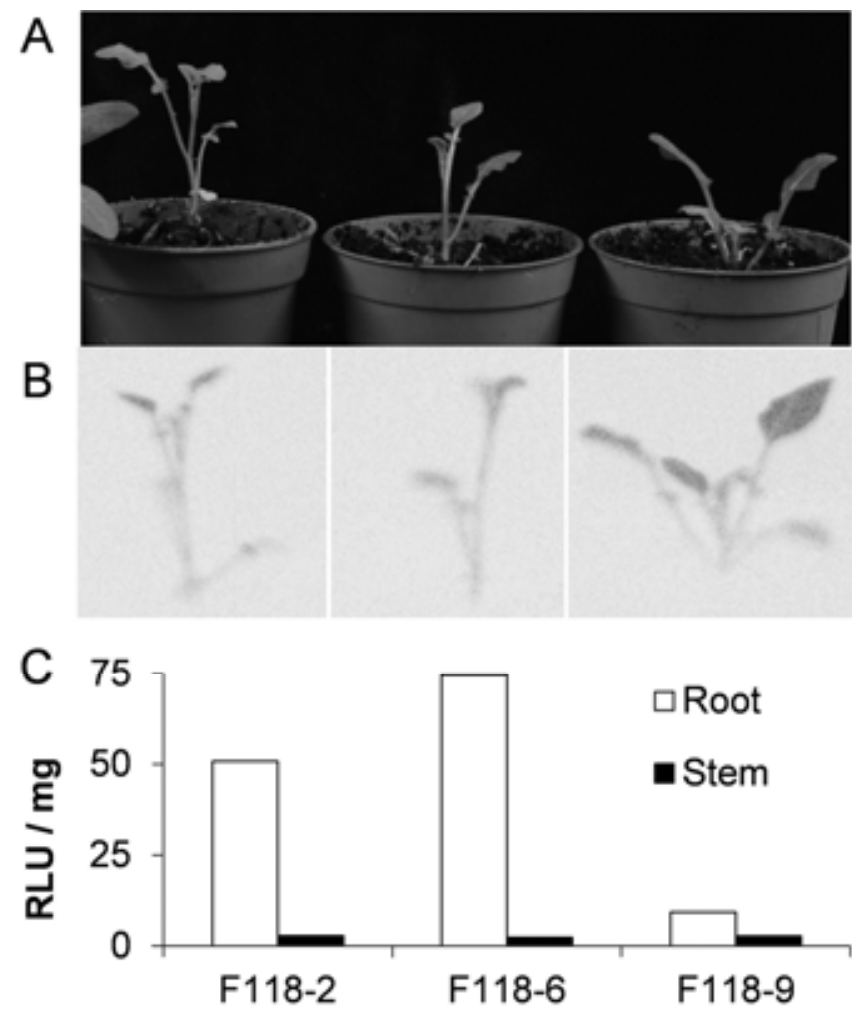

Fig. 5. Bacterial colonization on asymptomatic Solanum commersonii F118 plants. A, Light photograph of plants infected with UY031 Pps-lux but showing no wilting at 7 days after inoculation. B, Luminescence detection in the aerial parts of the plants in A. No signal could be detected throughout the stem. C, Bacterial load in plant tissues estimated by exposure of cut root or stem sections from plants in A to a luminometer. Light emission from the reporter strain is presented as relative luminescence units (RLU) per milligram of tissue. tive technique can finally be uprooted and evaluated for latent infections in the roots using the highly sensitive luminometer measurements. All these methodologies are easy to implement, cheap, and fast to carry out because they do not require sophisticated reagents or equipment. In addition, luminescence simplifies the quantification of bacterial counts from infected plants, usually performed by time-consuming tissue homogenization, plating, and counting of CFU.

The work presented here constitutes a proof-of-concept of the potential of using the $\operatorname{lu} x C D A B E$ operon in plant-bacteria interactions. Furthermore, the development of this methodology will be useful in breeding programs to analyze potato colonization in a high-throughput and accurate way. This will enable the discarding of tolerant genotypes carrying latent infections at early stages of the selection program, ensuring the success of the process. In addition, the availability of live imaging of bacterial colonization in planta may also be applied in the future to the study of $R$. solanacearum interaction with its hosts to understand basic aspects of this disease.

\section{MATERIALS AND METHODS}

\section{Bacterial strains and growth conditions.}

The $R$. solanacearum reporter strain was constructed using a UY031 wild-type background (phylotype IIB, sequevar 1), a highly aggressive strain isolated from a potato tuber with typical bacterial wilt symptoms in Uruguay in 2003 (Siri and Pianzzola 2011; Siri et al. 2009). R. solanacearum was routinely grown at $30^{\circ} \mathrm{C}$ in rich $\mathrm{B}$ medium or Boucher's minimal medium (MM) supplemented with $20 \mathrm{mM}$ L-glutamate (Sigma-Aldrich, St. Louis) as a carbon source (Boucher et al. 1985; Monteiro et al. 2012a). Tetracycline (at 10 and $5 \mu \mathrm{g} / \mathrm{ml}$ in liquid cultures) and gentamicin (75 and $5 \mu \mathrm{g} / \mathrm{ml}$ in liquid cultures) were used for selection in $R$. solanacearum. Escherichia coli (Mach1; Life Technologies, Paisley, U.K.) was

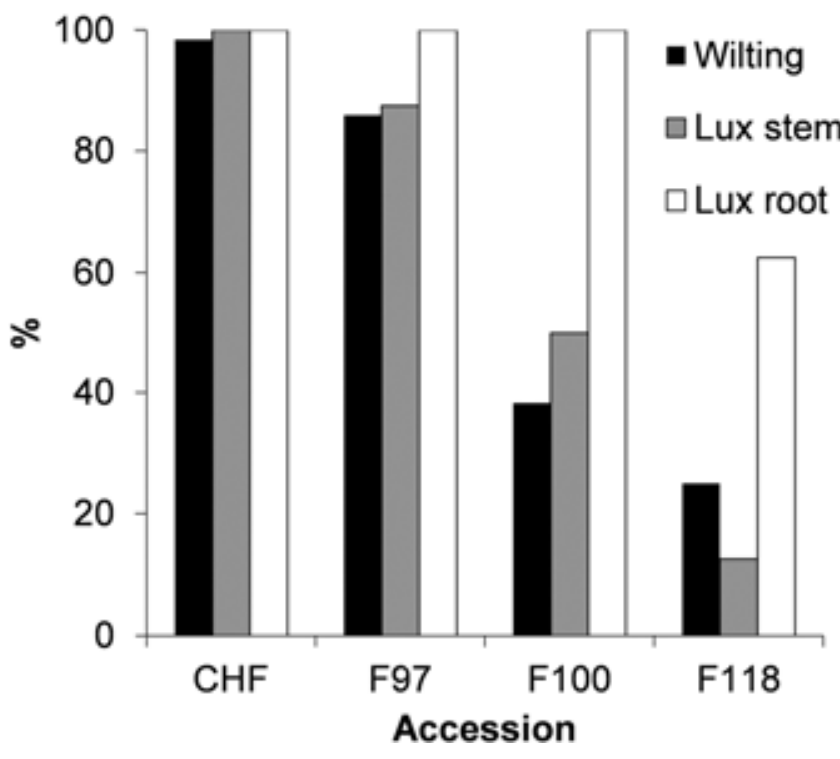

Fig. 6. Evaluation of Solanum commersonnii and S. tuberosum cultivars for resistance to bacterial wilt using a luminescent bacterial. The susceptible $S$. tuberosum cultivar ('Chieftain' $[\mathrm{CHF}]$ ) and three $S$. commersonii accessions (susceptible F97 and tolerant F100 and F118) were soil inoculated with strain UY031 Pps-lux and the disease was evaluated at 7 postinoculation, when all CHF plants were wilted. Black bars indicate the mean percentage of wilting symptoms at day 7 , gray bars the percentage of plants in which luminescence was detected in the aerial parts with a light imaging system, and white bars the percentage of plants where light was detected in the roots using a luminometer. Percentages were calculated from the whole set of inoculated plants $(n=8)$ for each genotype. 
grown at $37^{\circ} \mathrm{C}$ in Luria and Bertani broth (LB) (Sambrook et al. 2000). Bacterial growth was monitored by measuring $\mathrm{OD}_{600}$.

DNA cloning and integration of constructs into the $R$. solanacearum chromosome.

The chloroplast promoter PpsbA was polymerase chain reaction (PCR) amplified from plasmid pDSK-GFPuv (Wang et al. 2007) using primers that added AvrII and KpnI restriction sites upstream and downstream of the sequence, respectively. This PCR fragment was cloned into pGEM-T-EASY (Life Technologies), giving rise to pG-Pps. The $P p s b A$ promoter was then excised from pG-Pps using AvrII-KpnI and cloned into the same sites of pRCG-GWY (Monteiro et al. 2012b), creating the plasmid pRCG-Pps-GWY. Finally, to generate pRCG-Ppslux, an SfiI-KpnI fragment containing the entire LuxCDABE operon, excised from plasmid pRCGent-Pep-lux (Monteiro et al. 2012b), was cloned into the same sites of pRCG-Pps-GWY. This plasmid bears the PpsbA::LuxCDABE reporter fusion and a gentamycin-resistance gene, all flanked by two homology regions for recombination into the bacterial chromosome. Similarly, pRCG-Pps-GFP was created by cloning a $K p n \mathrm{I} / B g l \mathrm{II}$ fragment from plasmid pG-GFPuv (Monteiro et al. 2012b) into the same sites of pRCG-Pps-GWY. PCR amplifications were performed with the proofreading Pfx DNA polymerase (Life Technologies) following the manufacturer's conditions, and other general molecular biology techniques were performed are described by Ausubel and associate (1994).

Genetic elements cloned in pRCG plasmids were introduced into $R$. solanacearum UY031 in a two-step process. First, two homology regions flanking a tetracycline resistance gene born in pCOMP-PhII (Monteiro et al. 2012b) were inserted via homologous recombination into a permissive site of the UY031 genome after natural transformation using the plasmid linearized by $S s p$ I. The resulting UY031comp strain contains two sequences in the chromosome where DNA elements carried by pRC plasmids can be targeted by double recombination. A second transformation of the resulting UY031comp strain with linearized pRCG plasmids and selection of double recombination events gave rise to UY031 Pps-lux, UY031 Pps-GFP, and UY031 Pep-lux. HindIII was used for linearization of pRCG-Pep-GFP before transformation and SfiI for pRCGent-Pep-Lux and pRCG-Pps-lux. R. solanacearum natural transformations were performed as described for strain GMI1000 (Boucher et al. 1985). Genomic insertions were confirmed by PCR as described by Monteiro and associates (2012b). At least two independent clones were used as biological replicas for all experiments. All plasmids and strains used in this work are summarized in Supplementary Table S3.

\section{Measuring lux reporter expression in culture.}

In order to determine whether the constructed strain UY031Pps-lux was able to express constitutively the lux reporter, we carried out time-course experiments measuring light emission using a luminometer (Berthold FB 12; Wildbad, Germany) and $\mathrm{OD}_{600}$ of the culture using a spectrophotometer (UV-1603 visible spectrophotometer; Shimadzu, Kyoto, Japan). UY031 Pps-lux was grown overnight in rich B medium and diluted in $20 \mathrm{ml}$ of $\mathrm{MM}$ in $15-\mathrm{ml}$ flasks to a final $\mathrm{OD}_{600}$ of 0.1 , and grown at $30^{\circ} \mathrm{C}$. Aliquots of the samples $(1 \mathrm{ml}$ each) were taken every hour during $7 \mathrm{~h}$ to measure $\mathrm{OD}_{600}$ and light emission. Luminescence readings were expressed in RLU, which

\section{Screening of wilting symptoms}

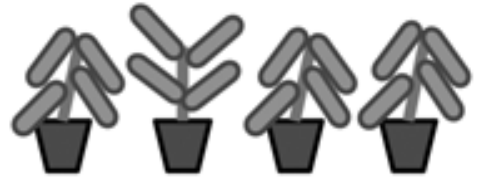

3. Luminescent detection of pathogen colonization

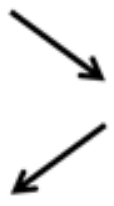

\section{Selection of symptom- less germplasm}

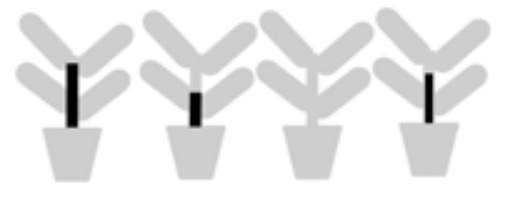

5. Evaluation of latent infection

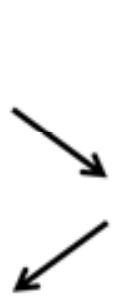

4. Selection of noncolonized genotypes in roots
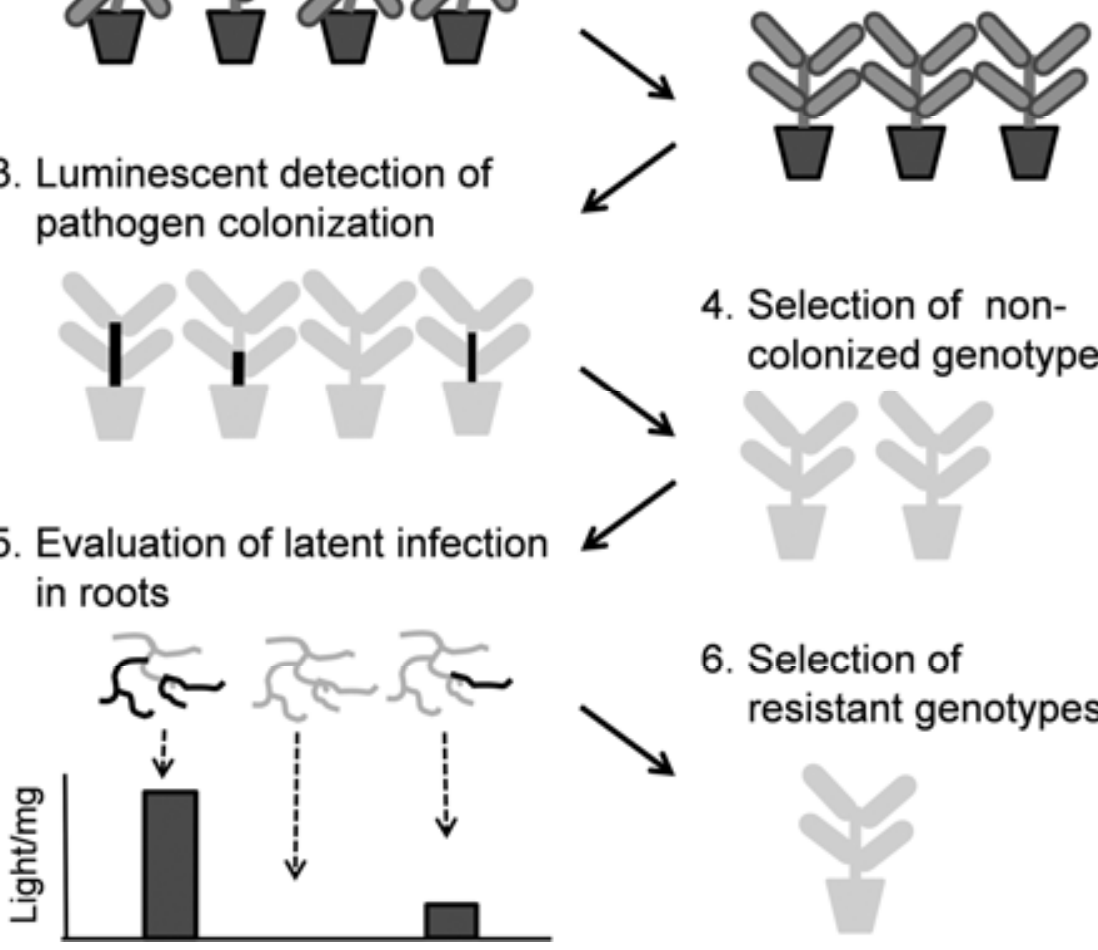

6. Selection of resistant genotypes

Fig. 7. Scheme of a plant breeding program aided by a luminescent Ralstonia solanacearum strain. Step 1: visual screening of wilting symptoms. Step 2: selection of symptomless germplasm. Step 3: use of luminescent $R$. solanacearum strain to detect pathogen colonization in asymptomatic germplasm. Step 4: selection of noncolonized genotypes (stem). Step 5: evaluation of latent infection of roots using the luminescent strain. Step 6: selection of resistant genotypes. 
correspond to the direct readings of the apparatus. The background levels of luminescence from untransformed bacteria in solution were approximately $30 \mathrm{RLU}$, slightly higher than the $10 \mathrm{RLU}$ used as background when luminescence was measured from plant tissues (discussed above).

\section{Plant material and growth conditions.}

S. tuberosum CHF (susceptible control) and three F1 plants obtained from a cross between two $S$. commersonii accessions with contrasting resistance against $R$. solanacearum (F97: susceptible, and F100 and F118: tolerant) from the germplasm collection at the National Institute for Agricultural Research (INIA, Las Brujas, Uruguay) (Gonzalez et al. 2013) were used for this study. Plants were micropropagated in vitro from single-node pieces growing on Murashige and Skoog (MS) agar medium supplemented with sucrose at $30 \mathrm{~g} /$ liter, and maintained at $22^{\circ} \mathrm{C}$ with a cycle of $16 \mathrm{~h}$ of light and $8 \mathrm{~h}$ of darkness. After 2 weeks, plantlets were transferred into pots containing TREF soil mix and grown for 1 week in a greenhouse at 22 to $25^{\circ} \mathrm{C}(50$ to $60 \%$ relative humidity $[\mathrm{RH}]$ ) and then for an additional week in a growth chamber at $27^{\circ} \mathrm{C}$ and $65 \% \mathrm{RH}$ with a photoperiod of $12 \mathrm{~h}$ of light. For long-term (up to 9 months) in vitro maintenance of the $S$. commersonii and $S$. tuberosum clones, plants were kept at $22^{\circ} \mathrm{C}$ with a cycle of $16 \mathrm{~h}$ of light and $8 \mathrm{~h}$ of darkness in a preservation medium. Preservation medium contains $20 \mathrm{ml}$ of MS without vitamins, $25 \mathrm{~g}$ of sucrose, $40 \mathrm{~g}$ of Dsorbitol, $8 \mathrm{~g}$ of agar, and $\mathrm{pH}$ adjusted to 5.8.

\section{Plant inoculation and disease rating.}

Four-week-old plants were drench inoculated with bacterial suspensions. To prepare inocula, bacterial strains were grown overnight in liquid rich B medium (Boucher et al. 1985; Monteiro et al. 2012a) at $30^{\circ} \mathrm{C}$ with shaking at $200 \mathrm{rpm}$. Cells were pelleted by centrifugation, suspended in water, and spectrophotometrically adjusted to $10^{7} \mathrm{CFU} / \mathrm{ml}$. Inoculum concentration was confirmed by dilution plating on rich $\mathrm{B}$ agar medium. Inoculation was performed by pouring $40 \mathrm{ml}$ of the $10^{7}$ $\mathrm{CFU} / \mathrm{ml}$ suspension into each pot. Prior to inoculation, roots were slightly damaged by making three holes in the soil of each pot with a disposable $1-\mathrm{ml}$ pipette tip ( $2 \mathrm{~cm}$ deep).

For disease rating, eight plants were inoculated with each strain in a complete randomized block design in two independent experiments. For bacterial visualization experiments, sets of at least 12 plants were inoculated in parallel in a randomized design in four independent experiments. After inoculation, plants were maintained in a growth chamber at 27 to $28^{\circ} \mathrm{C}$ $(65 \% \mathrm{RH})$ with a 12 -h photoperiod. Disease development was recorded daily using an ordinal disease index scale ranging from 0 (no wilting symptoms) to 4 (all leaves wilted) for up to 15 days after inoculation (Winstead and Kelman 1952). For comparisons between different strains, pathogenicity was estimated by the AUDPC based on the average wilt scoring for each combination of strain and host. AUDPC data from trials of experiments performed on the same host were combined, and analysis of variance was conducted to identify significant effects of trials, strains, and interactions between the main effects of trials and strains. Means were pooled across trials when no significant effects involving trials were found.

\section{Bacterial visualization and quantification.}

Bacteria colonization of the plant tissue was visualized using the Fuji Film LAS4000 light imager system, with the chemiluminescence method, an incremental exposure time of $2 \mathrm{~min}$, and the sensitivity/resolution set to high binning. Because this is a nondestructive technique, plants were evaluated daily until they died. In addition, we indirectly quantified the amount of bacteria present in plants using a destructive method, by collecting $1-\mathrm{cm}$ sections of the root system or the stem from $1 \mathrm{~cm}$ above and below ground and directly measuring luminescence from the cut sections with a luminometer (Berthold FB 12). Each sample was weighted and the luminescence readings were corrected for the amount of tissue present in each sample and expressed in RLU per milligram of tissue. Background luminescence levels were set to 2 RLU by measuring luminescence from plants infected with an untransformed strain.

\section{ACKNOWLEDGMENTS}

This work was supported by grants SGR0052 and CONES2010-0030 from Comissionat per Universitats i Recerca of the Catalan Government (Generalitat de Catalunya), AGL2010-21870 from the Ministerio de Economía of the Spanish Government, and FMV_2009_1_3045 from the National Research Council in Uruguay (ANII). The work was also partially sponsored by a grant from the Fundació Solidaritat from Universitat de Barcelona. The work was carried out in the framework of project 109AC0373 (Ralstop), funded by the Ibero-American Program for Science Technology and Development (CYTED). V. Ferreira was allowed a travel fellowship from the CYTED project Ralstop and CSIC-Uruguay I+D Grupos 652 grant for a short stay in the lab of M. Valls. We thank L. Gutarra for her advice and for sharing her invaluable experience with us, M. Solé and F. Monteiro for interesting discussions, M. Solé for setting up the potato- $R$. solanacearum pathosystem, I. van DijK and F. Monteiro for constructing original plasmids (pG-Pps, pRCG-GWY and pRCGent-Peplux) used as sources of inserts for cloning, F. Vilaró and M. González for providing the $S$. commersonii genotypes used in this study, and S. Balcells for lending us a luminometer. A. P. Z. Cruz performed most experiments, contributed to the experimental design, data analyses, data interpretation drafting of the article and revised the article critically. V. Ferreira performed the experiments. M. J. Pianzzola revised the article critically. M. I. Siri performed experiments, contributed to the data interpretation and revised the article critically. N. S. Coll performed experiments, contributed to the experimental design, data analyses, data interpretation drafting of the article and critical revision of the article. M. Valls performed experiments, contributed to the experimental design, data analyses, data interpretation drafting of the article and critical revision of the article.

\section{LITERATURE CITED}

Angot, A., Peeters, N., Lechner, E., Vailleau, F., Baud, C., Gentzbittel, L., Sartorel, E., Genschik, P., Boucher, C., and Genin, S. 2006. Ralstonia solanacearum requires F-box-like domain-containing type III effectors to promote disease on several host plants. Proc. Natl. Acad. Sci. U.S.A. 103:14620-14625.

Ausubel, F. M., Brent, R., Kingston, R. E., Moore, D. D., Seidman, J. G., Smith, J. A., and Struhl, K. 1994. Current Protocols in Molecular Biology. John Wiley and Sons, New York.

Boucher, C. A., Barberis, P. A., Trigalet, A. P., and Demery, D. A. 1985. Transposon mutagenesis of Pseudomonas solanacearum: Isolation of Tn5-induced avirulent mutants. J. Gen. Microbiol. 131:2449-2457.

Carmeille, A., Caranta, C., Dintinger, J., Prior, P., Luisetti, J., and Besse, P. 2006. Identification of QTLs for Ralstonia solanacearum race 3-phylotype II resistance in tomato. Theor. Appl. Genet. 113:110-121.

Carputo, D., Aversano, R., Barone, A., Di Matteo, A., Iorizzo, M., Sigillo, L., Zoina, A., and Frusciante, L. 2009. Resistance to Ralstonia solanacearum of sexual hybrids between Solanum commersonii and S. tuberosum. Am. J. Potato Res. 86:196-202.

Caruso, P., Palomo, J. L., Bertolini, E., Álvarez, B., López, M. M., and Biosca, E. G. 2005. Seasonal variation of Ralstonia solanacearum biovar 2 populations in a Spanish river: Recovery of stressed cells at low temperatures. Appl. Environ. Microbiol. 71:140-148.

Denny, T. P. 2006. Plant pathogenic Ralstonia species. Pages 573-644 in: Plant-Associated Bacteria. S. S. Gnanamanickam, ed. Springer, Dordrecht, The Netherlands.

Elphinstone, J. G. 2005. The current bacterial wilt situation: A global overview. Pages 9-28 in: Bacterial wilt Disease and the Ralstonia solanacearum Species Complex. C. Allen, P. Prior, and A. C. Hayward, eds. American Phytopathological Society Press, St. Paul, MN, U.S.A.

Fan, J., Crooks, C., and Lamb, C. 2008. High-throughput quantitative luminescence assay of the growth in planta of Pseudomonas syringae chromosomally tagged with Photorhabdus luminescence luxCDABE. Plant J. 53:393-399.

Fegan, M., and Prior, P. 2005. How complex is the 'Ralstonia solanacearum' species complex? Pages 449-461 in: Bacterial Wilt: The Disease 
and the Ralstonia solanacearum Species Complex. C. Allen, P. Prior, and A. C. Hayward, eds. American Phytopathological Society Press, St. Paul, MN, U.S.A.

French, E. R., and De Lindo., L. 1982. Resistance to Pseudomonas solanacearum in potato. Specificity and temperature sensitivity. Phytopathology 72:1408-1412.

Galván, G., Fraguas, F., Quirici, L., Santos, C., Silvera, E., Siri, M. Villanueva, P., Raudiviniche, L., González, M., Torres, D., Castillo, A., Dalla Rizza, M., Vilaró, F., Gepp, V., Ferreira, F., and Pianzzola, M. J. 2006. Solanum commersonii: Una especie con gran potencial para el mejoramiento genético de papa por resistencia a Ralstonia solanacearum. Pages 87-102 in: Avances de investigación en recursos genéticos en el cono sur I. I. Procisur, ed. Procisur, Montevideo, Uruguay.

Genin, S., and Boucher, C. 2004. Lessons learned from the genome analysis of Ralstonia solanacearum. Annu. Rev. Phytopathol. 42:107-134.

Genin, S., and Denny, T. P. 2012. Pathogenomics of the Ralstonia solanacearum species complex. Annu. Rev. Phytopathol. 50:67-89.

Gonzalez, M., Galvan, G., Siri, M. I., Borges, A., and Vilaro, F. 2013. Resistencia a la marchitez bacteriana de la papa en Solanum commersonii Dun. Agrociencia 17:45-54.

Hawkes, J. G. 1994. Origins of cultivated potatoes and species relationships. Pages 3-42 in: Potato Genetics. J. E. Bradshaw and G. R. Mackay, eds. CAB International, Wallingford, U.K.

Hayward, A. C. 1991. Biology and epidemiology of bacterial wilt caused by Pseudomonas solanacearum. Annu. Rev. Phytopathol. 29:6587.

Hayward, A. C., and Pegg., K. G. 2013. Bacterial wilt of ginger in Queensland: Reappraisal of a disease outbreak. Australas. Plant Pathol. 42:235239

Hikichi, Y., Nakazawa-Nasu, Y., Kitanosono, S., Suzuki, K., and Okuno, T 1999. The behavior of lux-marked Ralstonia solanacearum in grafted tomato cultivars resistant or susceptible to bacterial wilt. Ann. Phytopathol. Soc. Jpn. 65:597-603.

Hirsch, J., Deslandes, L., Feng, D. X., Balague, C., and Marco, Y. 2002. Delayed symptom development in ein2-1, an Arabidopsis ethyleneinsensitive mutant, in response to bacterial wilt caused by Ralstonia solanacearum. Phytopathology 92:1142-1148.

Hong, J., Ji, P., Momol, M. T., Jones, J. B., Olson, S. M., Pradhanang, P., and Guven, K. 2005. Ralstonia solanacearum detection in tomato irrigation ponds and weeds. Pages 309-311 in: Proceedings of the First International Symposium on Tomato Disease, International Society for Horticultural Science, Orlando, FL, U.S.A.

Janse, J. D. 1996. Potato brown rot in western Europe-history, present occurrence and some remarks on possible origin, epidemiology and control strategies. EPPO Bull. 26:679-695.

Janse, J. D., van den Beld, H. E., Elphinstone, J., Simpkins, S., Tjou-TamSin, N. N. A., and van Vaerenbergh, J. 2004. Introduction to Europe of Ralstonia solanacearum biovar 2, race 3 in Pelargonium zonale cuttings. Plant Pathol. 87:147-155.

Kim-Lee, H., Moon, J. S., Hong, Y. J., Kim, M. S., and Cho, H. M. 2005. Bacterial wilt resistance in the progenies of the fusion hybrids between haploid of potato and Solanum commersonii. Am. J. Potato Res. 82:129-137.

Laferriere, L. T., Helgeson, J. P., and Allen, C. 1999. Fertile Solanum tuberosum $+S$. commersonii somatic hybrids as sources of resistance to bacterial wilt caused by Ralstonia solanacearum. Theor. Appl. Genet. 98:1272-1278.

Lebeau, A., Gouy, M., Daunay, M. C., Wicker, E., Chiroleu, F., Prior, P., Frary, A., and Dintinger, J. 2013. Genetic mapping of a major dominant gene for resistance to Ralstonia solanacearum in eggplant. Theor. Appl. Genet. 126:143-158.

Martin, C., and French, E. R. 1985. Bacterial Wilt of Potato: Pseudomonas solanacearum. International Potato Center, Lima, Peru.
Monteiro, F., Genin, S., van Dijk, I., and Valls, M. 2012a. A luminescent reporter evidences active expression of Ralstonia solanacearum type III secretion system genes throughout plant infection. Microbiology 158:2107-2116.

Monteiro, F., Sole, M., van Dijk, I., and Valls, M. 2012b. A chromosomal insertion toolbox for promoter probing, mutant complementation, and pathogenicity studies in Ralstonia solanacearum. Mol. Plant-Microbe Interact. 25:557-568.

Muthoni, J., Shimelis, H., and Melis, R. 2012. Management of bacterial wilt of potatoes: Opportunities for host resistance in Kenya. J. Agric. Sci. 4:64-78.

Narancio, R., Zorrilla, P., Robello, C., Gonzalez, M., Vilaro, F., Pritsch, C., and Dalla-Rizza, M. 2013. Insights on gene expression response of a characterized resistance genotype of Solanum commersonii Dun. against Ralstonia solanacearum. Eur. J. Plant Pathol. 136:823-835.

Peeters, N., Guidot, A., Vailleau, F., and Valls M. 2013. Ralstonia solanacearum, a widespread bacterial plant pathogen in the post-genomic era. Mol. Plant Pathol. 14:651-662.

Pianzzola, M. J., Zarantonelli, L., González, G., Franco Fraguas, L., and Vázquez, A. 2005. Genetic, phytochemical and biochemical analyses as tools for biodiversity evaluation of wild Solanum commersonii accessions. Biochem. Syst. Ecol. 33:67-78.

Qian, Y. L., Wang, X. S., Wang, D. Z., Zhang, L. N., Zu, C. L., Gao, Z. L., Zhang, H. J., Wang, Z. Y., Sun, X. Y., and Yao, D. N. 2012. The detection of QTLs controlling bacterial wilt resistance in tobacco ( N. tabacum L.). Euphytica 192:259-266.

Sambrook, J., Fritsch, E. F., and Maniatis, T. 2000. Molecular Cloning: A Laboratory Manual. Cold Spring Harbor Laboratory Press, Cold Spring Harbor, NY, U.S.A

Sequeira, L., and Rowe, P. R. 1969. Selection and utilization of Solanum phureja clones with high resistance to different strains of Pseudomonas solanacearum. Am. J. Potato Res. 46:451-462.

Siri, M. I., and Pianzzola, M. J. 2011. Genetic diversity and aggressiveness of Ralstonia solanacearum strains causing bacterial wilt of potato in Uruguay. Plant Dis. 95:1292-1301.

Siri, M. I., Galván, G. A., Quirici, L., Silvera, E., Villanueva, P., Ferreira, F., Fraguas, L. F., and Pianzzola, M. J. 2009. Molecular marker diversity and bacterial wilt resistance in wild Solanum commersonii accessions from Uruguay. Euphytica 165:371-382.

Swanson, J. K., Yao, J., Tans-Kersten, J., and Allen, C. 2005. Behavior of Ralstonia solanacearum race 3 biovar 2 during latent and active infection of geranium. Phytopathology 95:136-143.

Tung, P. X., Rasco, E. T., Jr., Vander Zaag, P., and Schmiediche, P. 1990 Resistance to Pseudomonas solanacearum in the potato: II. Aspects of host-pathogen-environment interaction. Euphytica 45:211-215.

Wang, J. F., Ho, F. I., Truong, H. T. H., Huang, S. M., Balatero, C. H., Dittapongpitch, V., and Hidayati, N. 2013. Identification of major QTLs associated with stable resistance of tomato cultivar 'Hawaii 7996' to Ralstonia solanacearum. Euphytica 190:241-252.

Wang, K., Kang, L., Anand, A., Lazarovits, G., and Mysore, K.S. 2007. Monitoring in planta bacterial infection at both cellular and whole-plant levels using the green fluorescent protein variant GFPuv. New Phytol. 174:212-223.

Wicker, E., Grassart, L., Coranson-Beaudu, R., Mian, D., Guilbaud, C., Fegan, M., and Prior, P. 2007. Ralstonia solanacearum strains from Martinique (French West Indies) exhibiting a new pathogenic potential. Appl. Environ. Microbiol. 73:6790-6801.

Williamson, L., Nakaho, K., Hudelson, B., and Allen, C. 2002. Ralstonia solanacearum race 3, biovar 2 strains isolated from geranium are pathogenic on potato. Plant Dis. 86:987-991.

Winstead, N. N., and Kelman, A. 1952. Inoculation techniques for evaluating resistance to Pseudomonas solanacearum. Phytopathology 42:628634. 